\title{
Results of Meteorological Rocket Experiments at Thumba ${ }^{1}$
}

\author{
M. S. V. RAO \\ Rocket Meleorological Office, Thumba, India \\ (Manuscript received 15 August 1966, in revised form 20 October 1966) \\ ABSTRACT
}

\begin{abstract}
A series of 23 successful meteorological rocket experiments were conducted at Thumba Equatorial Rocket Launching Station from July 1964 through July 1966.

An analysis of the data collected shows the following pattern of winds in the equatorial upper atmosphere. In the stratosphere, the wind flow is predominantly easterly. However, westerlies are observed above $25-30$ $\mathrm{km}$ in April and October $\rightarrow$ November. In the mesosphere westerlies become more frequent and are noticeable not only in the above months, but also in February through April. The transition to this pattern from the middle latitude wind regime seems to take place gradually in the subtropics.

From a study of the wind shears over Thumba, as well as from radar observations of the spread of chaff, it is noticed that during certain periods a region of high shears and pronounced turbulence manifests itself above $50 \mathrm{~km}$.

Further, from chaff dispersion studies, it has been possible to make a preliminary estimate of the diffusion coefficient in the stratosphere and mesosphere.
\end{abstract}

\section{Introduction}

In an earlier paper (Rao, 1965) the preliminary results of the first ten meteorological rocket soundings from Thumba were reported. Since then several more successful rocket experiments have been made, making a total of 23 , and further analysis carried out. This paper presents the consolidated results of all the meteorological rocket experiments at Thumba from July 1964 through July 1966.

Thumba is situated near the southern tip of India, very close to the magnetic equator. Its geographical coordinates are $8.5 \mathrm{~N}, 76.9 \mathrm{E}$. The current series of experiments at Thumba is providing data over the tropics, a region which is as yet barely understood.

The launchings at Thumba were spread out so that the equatorial upper atmosphere could be studied during different seasons. Further, the rocket firings were made on World Days; until the end of 1965 the experiments were conducted on IQSY World Days, and since then on World Days of the IUWDS International Geophysical Year Calendar. This has facilitated nearsynoptic study.

\section{The main experiment}

The rocket and payload. The single stage Judi-Dart rocket was used in the experiments. The Judi is an internal burning, solid propellant vehicle, with a peak acceleration of $250 \mathrm{~g}$. The Judi motor burns out in a little under $2 \mathrm{sec}$ at an altitude of about $1500 \mathrm{~m}$. The

1 This paper (with rocket winds up to May 1966 only) was presented at the Seventh International Space Science Symposium, Vienna, Austria, on 12 May 1966. dart then separates and rises further to an altitude of about $65 \mathrm{~km}$ in approximately $135 \mathrm{sec}$ from launch. The payload is then ejected by the explosion of a charge detonated by a pyrotechnic delay which is ignited initially at launch.

The payload in the Thumba experiments consisted of copper chaff filaments 2.1 inches long and 0.005 inch diameter. The length is chosen so as to match the wavelength of the tracking radar while the diameter is calculated to give the optimum fall rate for wind determination in the altitude region under exploration.

Collection of data and data reduction. The descent of the chaff cloud was followed by a mobile MPS-19 radar system $^{2}$ operating on $2830 \mathrm{MHz}$. While the antenna in the radar van of the MPS system automatically tracked the chaff, a number of charts in the computer van were simultaneously traced out (including an $X-Y$ plot, as well as altitude-time, horizontal range-time, and azimuth-time strip charts).

The principal data used in data reduction were those provided by the $X-Y$ plot and the altitude-time strip chart, the remaining charts being used for purposes of checking. The procedure adopted was a simple modification of the India Meteorological Department method for pilot balloon computations, and has been described in detail by Rao and Sikdar (1965).

\section{Results of the main experiment}

The results of the rocket firings are presented in Figs. 1 and 2.

2 During the last rocket launching reported in this paper, in addition to the MPS-19 radar, a French Cotal radar was also brought into use. 
Figs. 1a, 1b and $1 \mathrm{c}$ represent 19 cases where the results appear to be normal, with wind shears within reasonable limits.

Fig. 2 represents 4 cases in which the data seem questionable and indicative of the radar beam wandering between centers of concentration in the chaff cloud. The reason for reporting these cases in the present paper will become apparent from the discussion in Section 5.

The results reveal the following pattern of winds:

a) In the stratosphere (i.e., below $48 \mathrm{~km}$ ) the winds over Thumba are generally easterly during the major part of the year. This is brought out clearly in Fig. $3 \mathrm{a}$ representing the zonal winds in the different months. The stratospheric easterlies attain a maximum in JulyAugust with speeds at times exceeding $80 \mathrm{kt}$. The reversal of the stratospheric winds takes place mainly in April when the speeds are in the range $40-80 \mathrm{kt}$ and in October-November when weak westerlies of speed generally below $25 \mathrm{kt}$ prevail.

b) In the mesosphere (i.e., above $48 \mathrm{~km}$ ) during February through April, the winds are westerly and occasionally attain speeds of over $100 \mathrm{kt}$. Again, in October-November there are relatively weak westerlies in the range $10-30 \mathrm{kts}$. During the rest of the year the

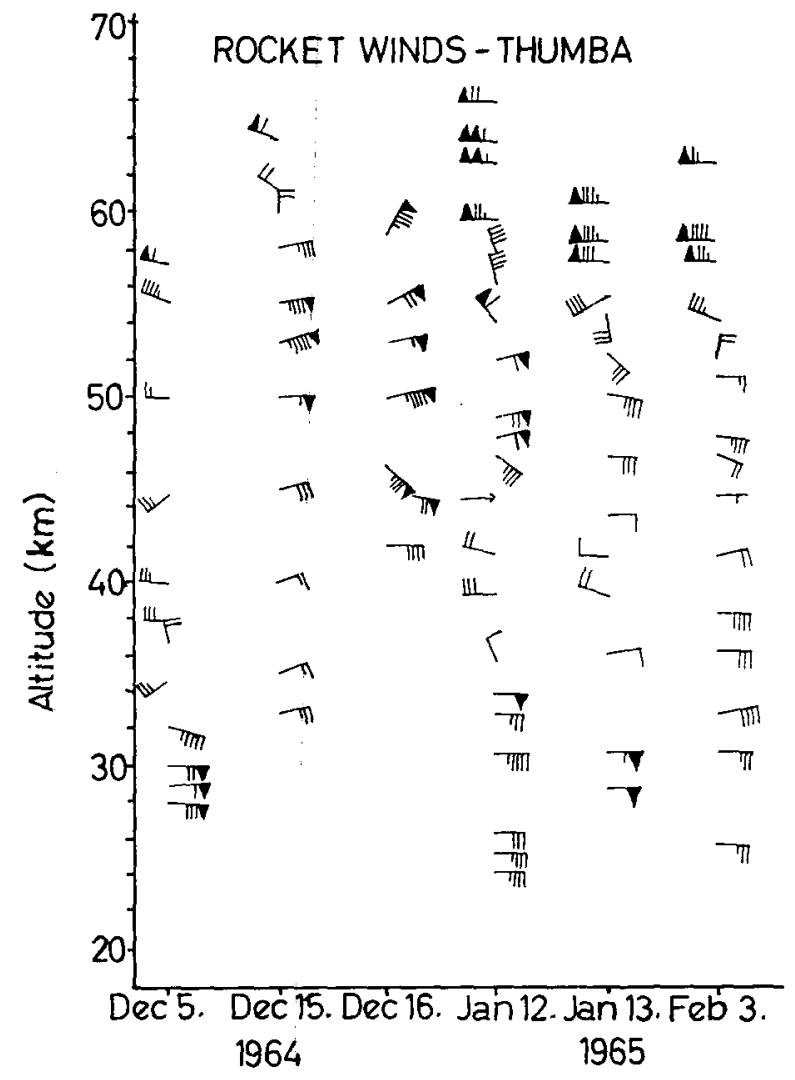

FIG. 1a. Thumba rocket firing results December 1964 through February 1965: full barbs, $10 \mathrm{kt}$; flags, $50 \mathrm{kt}$.

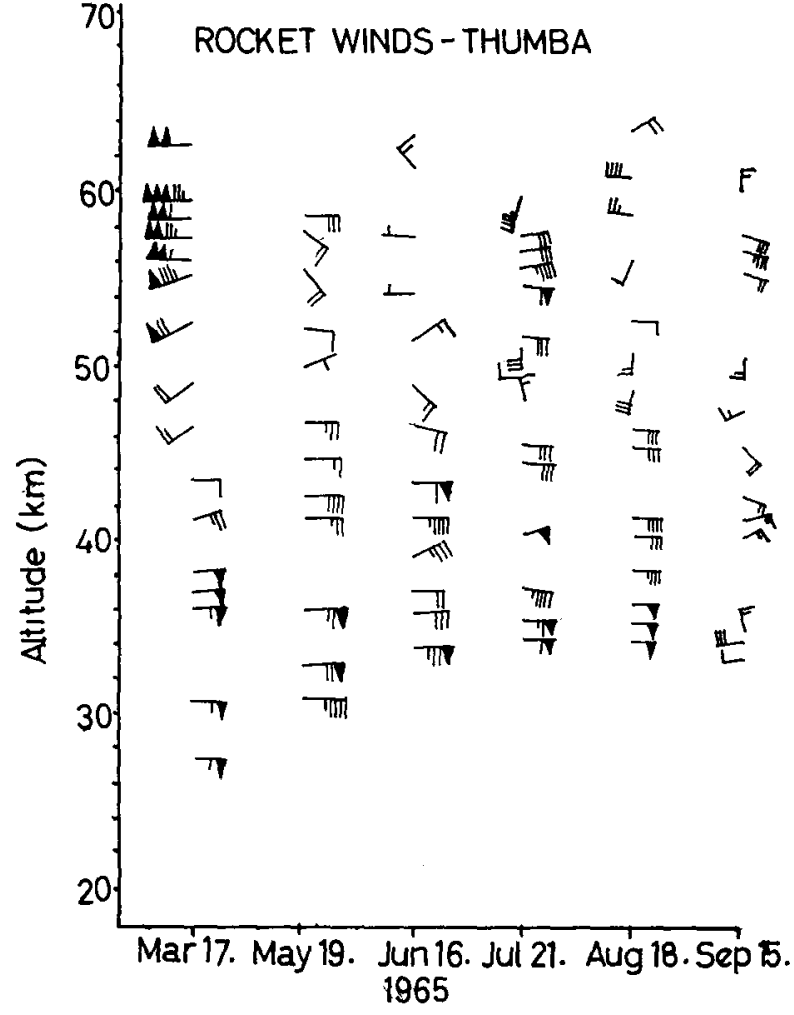

Fig. 1b. Same as Fig. 1a for March 1965 through September 1965.

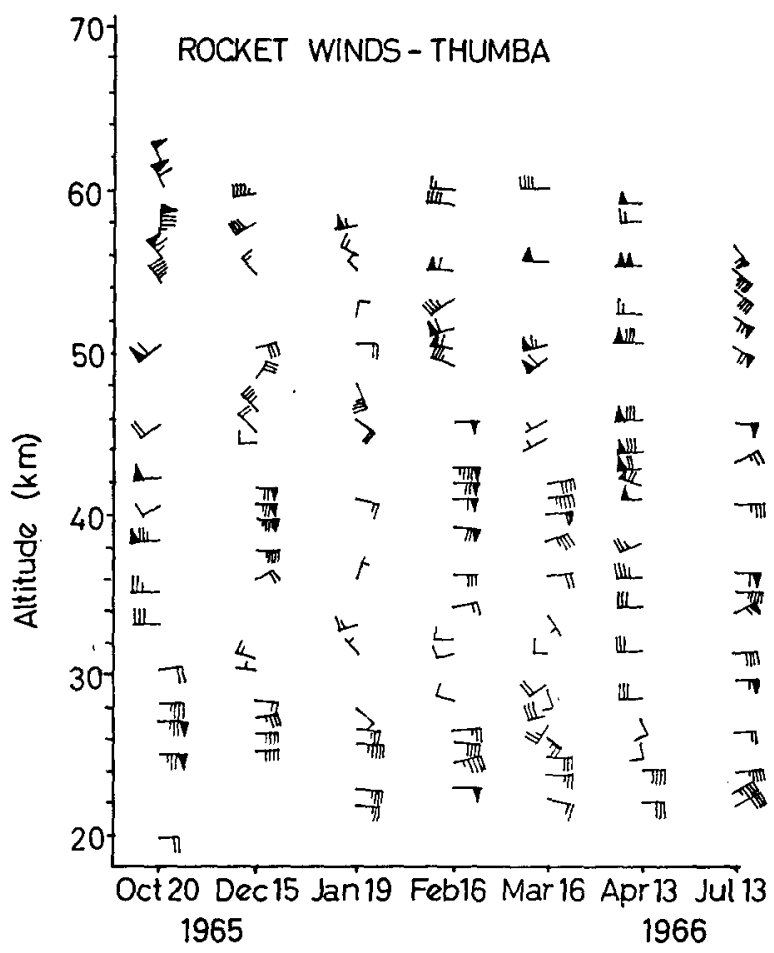

FIG. 1c. Same as Fig. 1a for October 1965 through July 1966. 


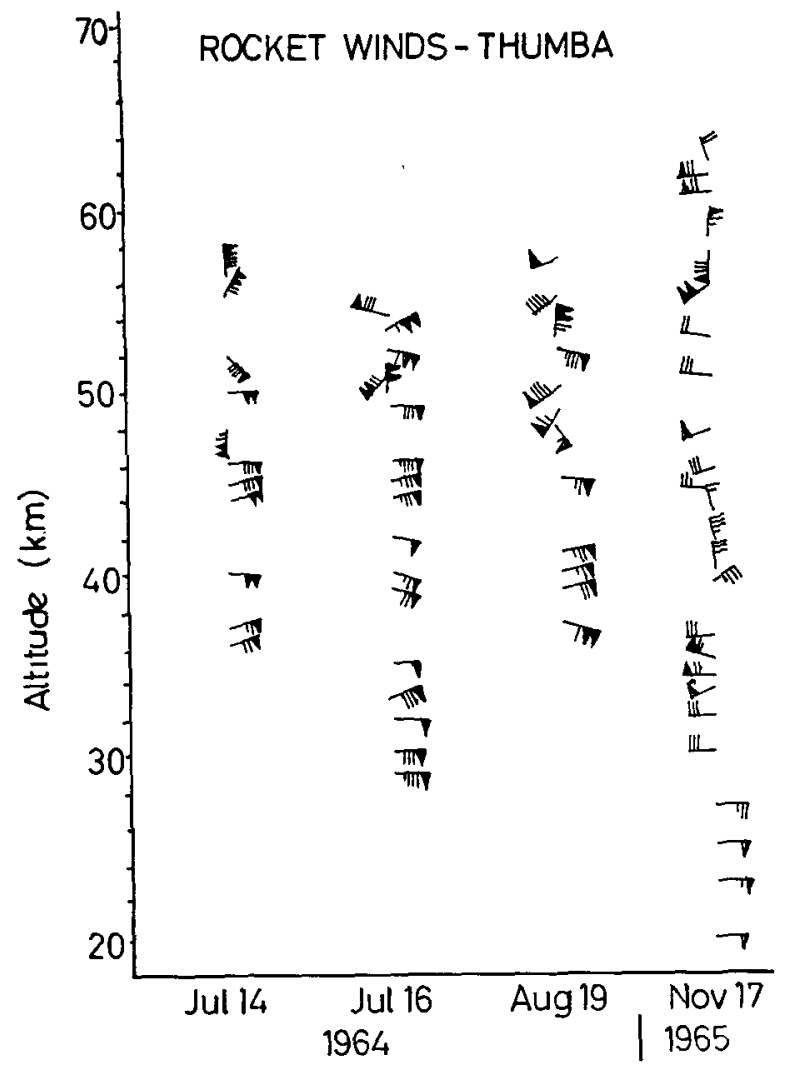

FIG. 2. Same as Fig. 1a for 4 cases in which the data seem to be questionable.

flow is predominantly easterly with speeds varying in a wide range, generally from 10 to $60 \mathrm{kt}$.

\section{Discussion}

Comparison with middle latitude circulation. The above results may be studied along with the upper atmospheric general circulation which has been described succinctly by Kellogg (1964). It is readily seen that the circulation pattern in the equatorial stratosphere differs from the typical pattern of temperate latitudes, where easterlies prevail in summer (anticyclonic circumpolar vortex) and strong westerlies in winter (cyclonic circumpolar vortex). Northern Hemisphere stratospheric charts such as those prepared by the Free University of Berlin often show a ridge line in the region $20-25 \mathrm{~N}$ in winter surrounding the polar cyclone. This is consistent with the easterlies, even in winter, of the equatorial stratosphere. It should also be remembered that there is a biennial oscillation in the equatorial stratosphere. The actual flow results from a combination of a basic easterly flow and the annual and biennial oscillations, at times modified by migratory low latitude systems

The mesospheric circulation conforms to a considerable degree with the middle latitude circulation. The
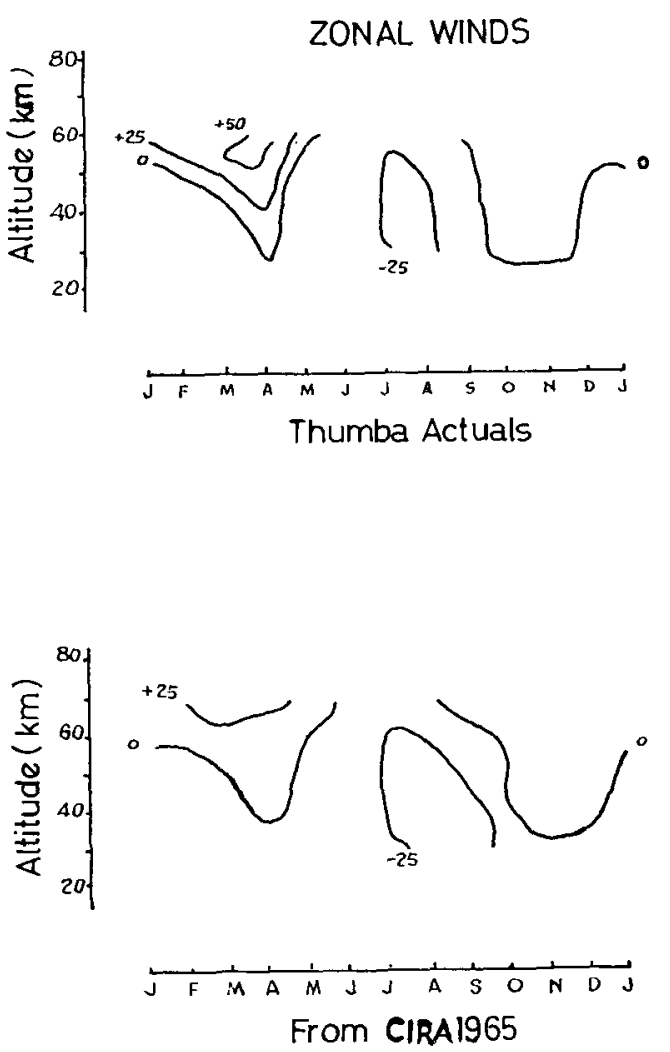

(b)

Frg. 3. Height-time cross sections of zonal winds at $8.5 \mathrm{~N}$ (winds in $\mathrm{m} \mathrm{sec}^{-1}$, westerlies positive): (a), Thumba actual winds; (b), from CIRA (1965).

westerlies are strong in the early part of the year. Easterlies prevail from May to September.

Comparison with CIRA 1965. The winds at $8.5 \mathrm{~N}$ obtained by interpolation of the tables presented by Groves (1965) in COSPAR International Reference Atmosphere 1965 are shown as a height-time cross section in Fig. 3b. The Thumba actual winds in Fig. 3a may be compared with these. The agreement is indeed good. The only significant variation seems to be that the actual winds observed in the mesosphere over Thumba in March and April appear to be stronger than the corresponding winds in the COSPAR reference atmosphere.

Comparison with Pakistan rocketsonde results. The results of Thumba rocket soundings were compared with similar results of Sonmiani, Pakistan, provided by Rahmatullah and Jafri (1965). The winter westerlies at Sonmiani penetrate for a longer duration and more deeply into the stratosphere than those at Thumba, as can be seen in Figs. $4 \mathrm{a}$ and $4 \mathrm{~b}$. Sonmiani winds conform better, on the whole, to the mid-latitude pattern shown in Fig. 4c, which is drawn from the data presented by Batten (1961), and by Faust and Soos (1965). Thus, the change from the mid-latitude wind regime to the equatorial regime appears to take place gradually through the subtropical belt. 
PERIODS OF EASTERLIES AND WESTERLIES
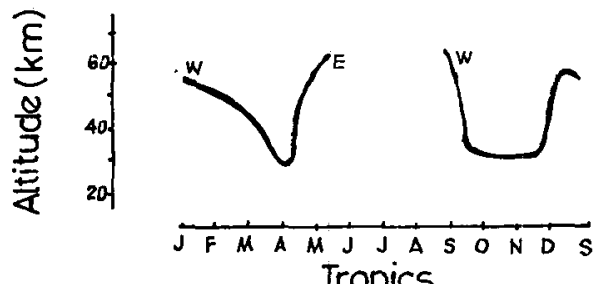

Tropics
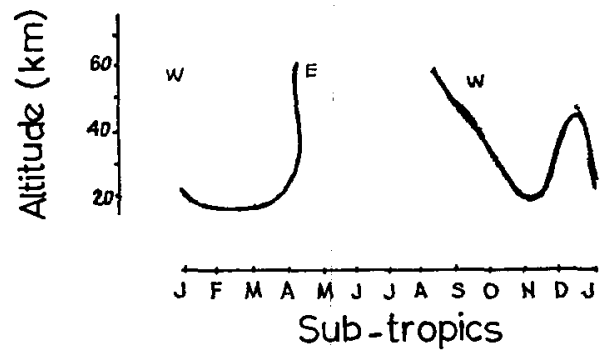

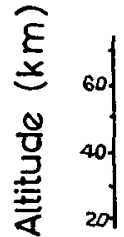

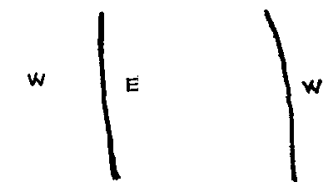

(b)

(c)

JFMAMJJASON D J

Temperate Latitudes

FIG. 4. Height-time cross sections showing the periods of westerlies and easterlies at different latitude regions: (a), based on Thumba data; (b), based on Sonmiani data; (c) based on data from Batten (1961) and from Faust and Soos (1965).
Components and shears. The N-S and E-W components of the rocket winds at Thumba were worked out. Fig." 5 presents a few samples. Below the components of the rocket winds are shown those of the rawins obtained at almost the same time. These diagrams show clearly that the flow is predominantly zonal. (One sample of the components from doubtful data is shown in Fig. 6.)

Wind shears were computed by taking vector differences at $1-\mathrm{km}$ intervals, for each rocket sounding. The magnitudes averaged separately for the periods JuneAugust and December-February are shown in Figs. 7a and $7 \mathrm{~b}$. The mean shears are slightly higher in the mesosphere than in the stratosphere. There is perhaps a. small peak in the shear value in the vicinity of $34 \mathrm{~km}$ in the stratosphere and another peak in the vicinity of $53 \mathrm{~km}$ in the mesosphere.

The four doubtful rocketsonde observations yield incredibly large shears in the mesosphere. Fig. 8 represents the mean shear during the Indian monsoon period, when these cases are also taken into consideration.

The shear magnitudes have been further averaged in certain regions of altitude, and are furnished in Table 1.

\section{A subsidiary experiment}

Chaff dispersion study. The spread of chaff was studied at Thumba making use of ground radar. The width of the image on the A-scope of the MPS-19 radar was noted at intervals of $\frac{1}{2}$ min. Further, photographs were taken at short intervals of the luminous A-scope dial along with a stop-watch placed by its side

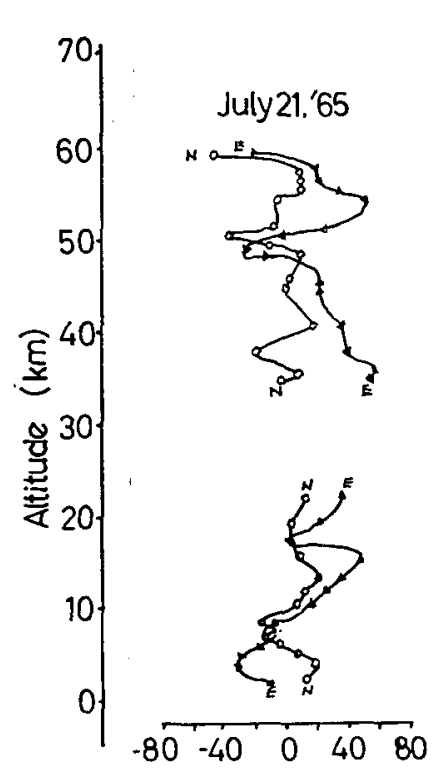

N-S AND E-W COMPONENTS.

\section{of Thumba Rocket Winds}
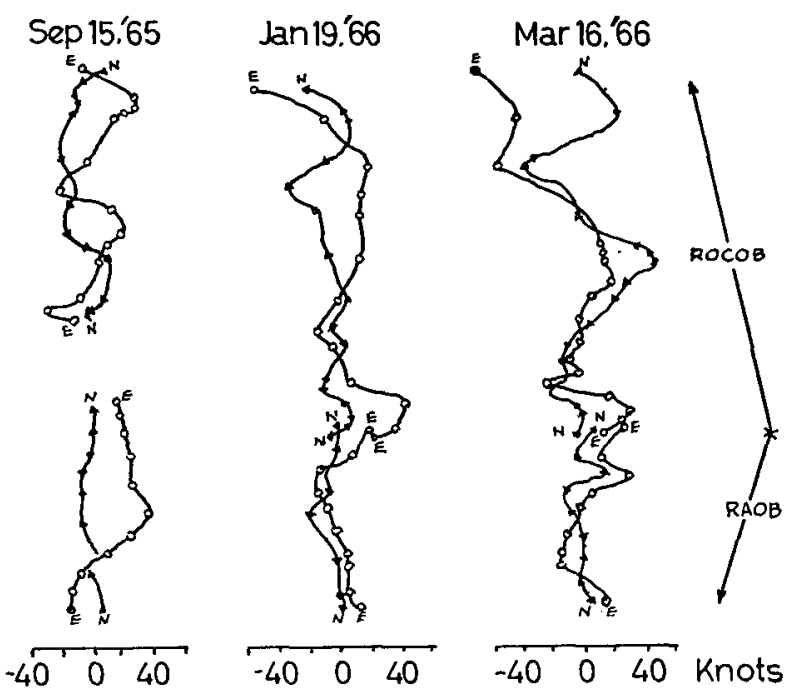

FIG. 5. Meridional and zonal components of four typical rocket winds of Thumba. Rawin components are shown in lower part. 
and illuminated by a flashlight bulb. A representative photograph is reproduced in Fig. 9.

These observations reveal, in certain periods, an unusually rapid rate of chaff spread. In most of the rocket experiments, it took more than $20 \mathrm{~min}$ to fill in the 2000-yard gate width of the A-scope. During the two experiments in July 1964, however, only 3 -min was required for the gate to fill in. In August 1964, the chaff width reached 2000 yards in about 6 min. Again, on 17 November 1965, the time taken was $6 \frac{1}{2} \mathrm{~min}$. These observations occurred precisely on the same occasions when incredibly high shear was noticed in the mesospheric wind profile. As a result, these two types of observations may be discussed together.

First, it will be noticed that the winds in the four rocketsondes presented in Fig. 2 appear to be questionable only above $48 \mathrm{~km}$. The question, therefore, arises why radar hunting should cease once the spreading chaff-cloud descends into the stratosphere.

Secondly, on these four occasions, during the first few minutes of radar tracking, an unusually fast rate of chaff-spread was recorded. It may well be asked why such exceptional chaff-spread should occur only on some occasions. (As the mean chaff level is $50 \mathrm{~km}$ at 6 $\min$ and $48 \mathrm{~km}$ at $7 \mathrm{~min}$, the region where this spread was observed is the mesosphere.)

A plausible answer to the above questions is that during certain periods there is severe turbulence in the

\section{N-S AND E-W COMPONENTS of Thumba Rocket Winds}

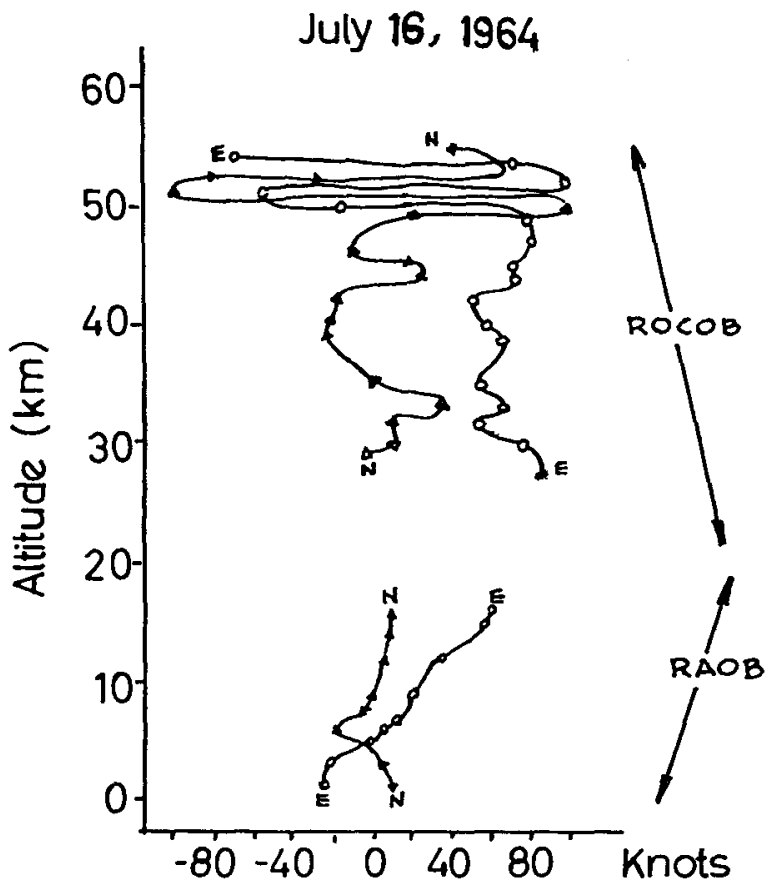

FIG. 6. A sample of wind components from the data in Fig. 2.
TABLE 1. Average shear in $\mathrm{m} \mathrm{sec}^{-1} \mathrm{~km}^{-1}$. (Figures in parentheses are the magnitudes when the doubtful cases are also considered.)

\begin{tabular}{|c|c|c|c|}
\hline & $\begin{array}{l}\text { Stratosphere } \\
30-48 \mathrm{~km}\end{array}$ & $\begin{array}{r}\text { Meso } \\
48-55 \mathrm{~km}\end{array}$ & $55-60 \mathrm{~km}$ \\
\hline $\begin{array}{l}\text { Jun. } \\
\text { to } \\
\text { Aug. }\end{array}$ & $\begin{array}{c}5.7 \\
(7.7)\end{array}$ & $\begin{array}{c}6.3 \\
(41.4)\end{array}$ & $\begin{array}{c}6.0 \\
(5.6)\end{array}$ \\
\hline $\begin{array}{c}\text { Dec. } \\
\text { to } \\
\text { Feb. }\end{array}$ & 5.1 & 7.3 & 6.1 \\
\hline
\end{tabular}

equatorial mesosphere giving rise to 1 ) quick chaffspread and 2) radar hunting which in turn either causes or increases irregularities in the computed winds. Thus, although the actual values of the winds (and, therefore, of the shears deducible from them) in the mesospheric profiles in Fig. 2 are doubtful, they are symptomatic of marked turbulence, just as the high rate of expansion of the chaff cloud is also indicative of the same condition.

The diffusion coefficient. From the data on the spread of chaff, an attempt was made to estimate

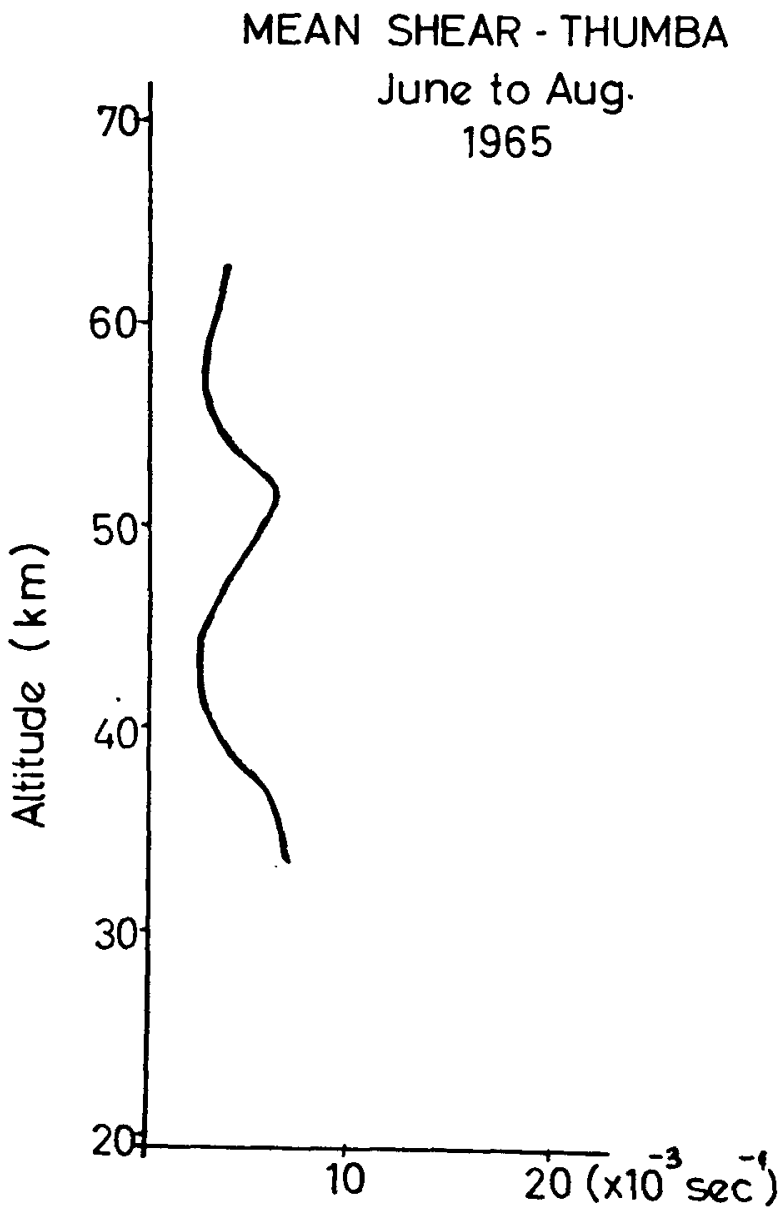

FIG. 7a. Mean wind shears over Thumba $\left(10^{-3} \mathrm{sec}^{-1}\right)$ for June through August 1965 


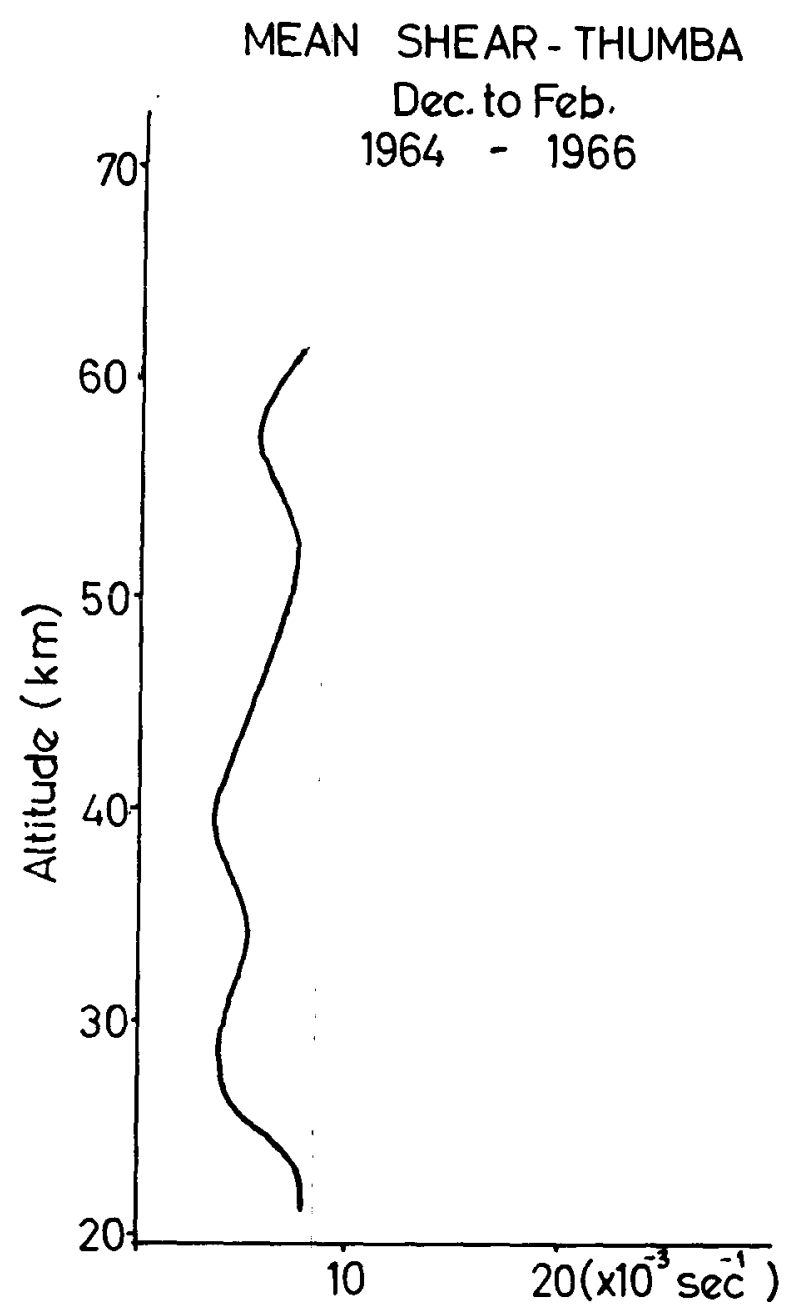

FIG. 7b. Same as Fig. 7a for December through February 1964, 1965, 1966.

the eddy diffusion coefficient, from two slightly different approaches.

In the first method it was assumed that 1) the dispersion of chaff is by eddies much larger in scale than the individual chaff filament, and 2) radar reflection becomes undetectable when the number density of chaft dipoles falls below a certain value.

Based on these assumptions, the following equation was developed (see Appendix) relating the growth of chaff cloud to the eddy diffusion coefficient, i.e.,

$$
W^{2} t^{-1}+55.26 K \log _{10} t+C=0,
$$

where $W$ is the width of the chaff cloud at time $t$ and $K$ is the diffusion coefficient.

In the second method, an attempt was made to

TABLE 2. Diffusion coefficient in $\mathrm{cm}^{2} \mathrm{sec}^{-1}$.

\begin{tabular}{lcc} 
& Method 1 & Method 2 \\
\hline Mesosphere (above $48 \mathrm{~km}$ ) & $2 \times 10^{6}$ & $3 \times 10^{6}$ \\
Stratosphere (below $48 \mathrm{~km})$ & $3 \times 10^{5}$ & $1 \times 10^{6}$ \\
\hline
\end{tabular}

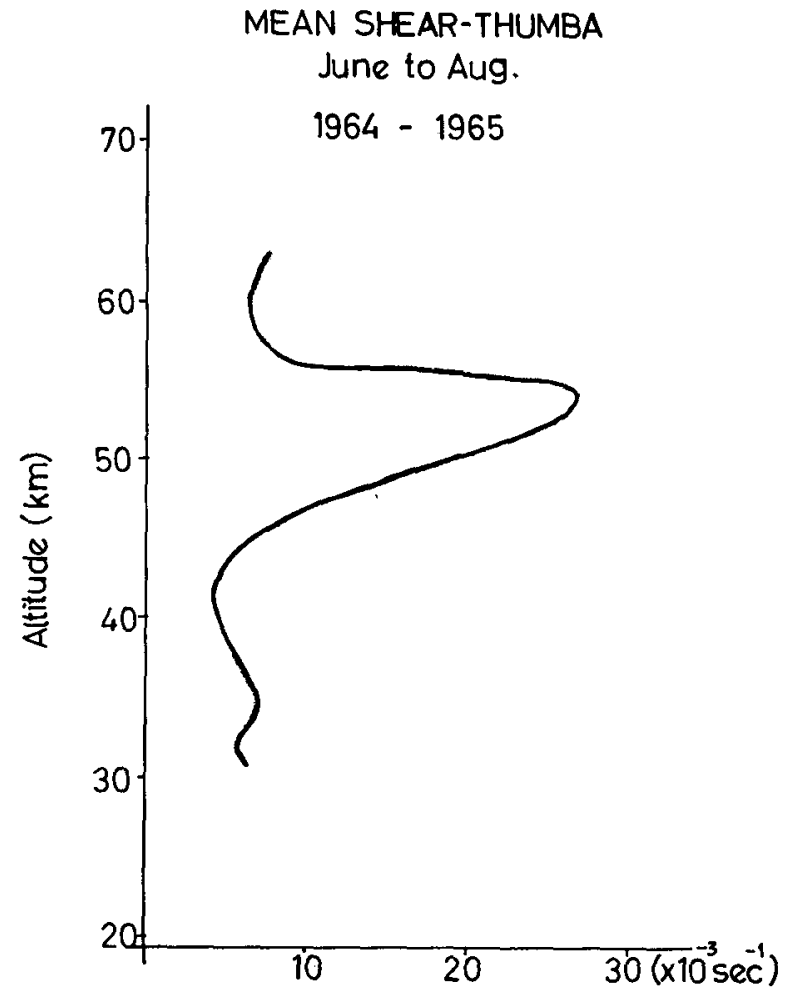

FIg. 8. Same as Fig. 7 a for June through August 1964, 1965, i.e. also including the questionable data.

estimate the standard deviation $\sigma$ of the chaff elements at various intervals of time. The diffusion coefficient was then evaluated from the relationship

$$
\sigma^{2}=2 K t .
$$

It may be added that the curves of chaff width versus time were carefully examined and data were only utilized during periods when the spread was free from suspicion of bird-nesting.

Preliminary estimates resulting from the above analysis are given in Table 2. (Seasonal and other

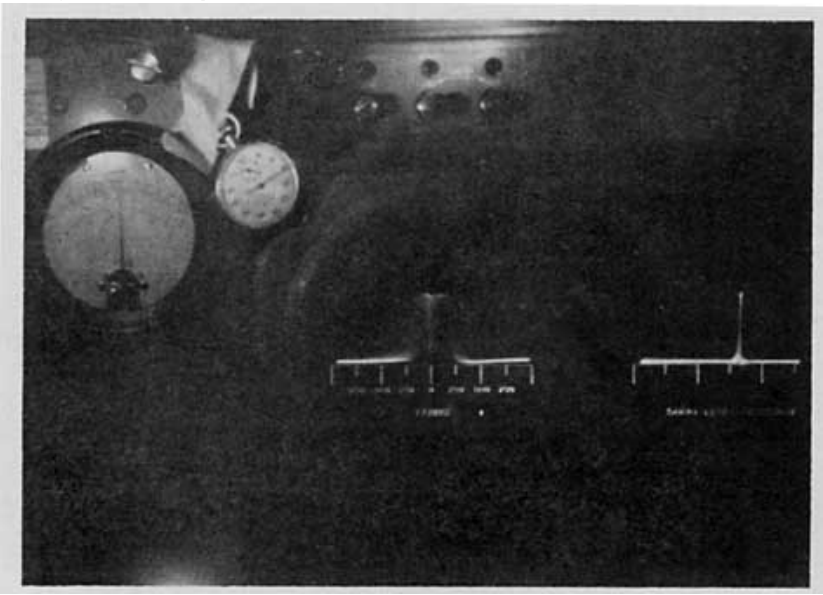

FIG. 9. Photograph of A-scope of MPS-19 radar with the AGC meter and a stop watch. 
variations can be discussed only after more soundings and further study.)

\section{Conclusions}

From the main and subsidiary experiments described above the following conclusions may be drawn:

1) In the equatorial stratosphere the winds are predominantly easterly except during the two intervals ${ }^{3}$ April and October-November.

2) In the equatorial mesosphere the winds are in general westerly during February through April and again in October-November. During the rest of the year, they are mainly easterly.

3) The transition from the middle latitude circulation to the above equatorial pattern appears to take place gradually in the subtropics.

4) At certain periods, a regime of pronounced shears and marked turbulence seems to prevail in the equatorial mesosphere, especially between 48 to $55 \mathrm{~km}$.

5) A preliminary estimate shows that the eddy diffusion coefficient in the equatorial stratosphere and mesosphere has an order of magnitude $10^{6} \mathrm{~cm}^{2} \mathrm{sec}^{-1}$. It is three or more times higher in the lower mesosphere than in the upper stratosphere.

Acknowledgments. This investigation was made possible due to the collaboration of the USA National Aeronautics and Space Administration, the Indian Committee on Space Research and the India Meteorological Department. I am thankful to the staff of the Thumba Equatorial Rocket Launching Station for their cooperation, and in particular, I am indebted to the Electronics Group for recording chaff width and other data according to my requirements.

\section{APPENDIX}

The basic argument used in deriving an equation to compute the diffusion coefficient is as follows. Let $\rho$ be the number density of chaff filaments. The diffusion equation is $\partial \rho / \partial t=K \nabla^{2} \rho$, where $K$ is the diffusion coefficient. As a first approximation, spherical symmetry may be supposed. A general solution of this equation satisfying spherical symmetry requirements is $\rho=A t^{-3 / 2} \exp \left\{-r^{2} / B t\right\}$ if $B=4 K$.

It seems reasonable to assume that when $\rho$ falls below a critical value $\rho_{c}$, radar reflection becomes undetectable. If this happens at a distance $r_{c}$ from the center of the chaff cloud (see Fig. 10), then the width observed on

${ }^{3}$ This conclusion is to be regarded as tentative. As has been stated before, the stratospheric wind is really a combination of the basic flow, annual, and quasi-biennial components, modified at times by migratory pressure systems. The quasi-biennial component may alter the "intervals" in future years.

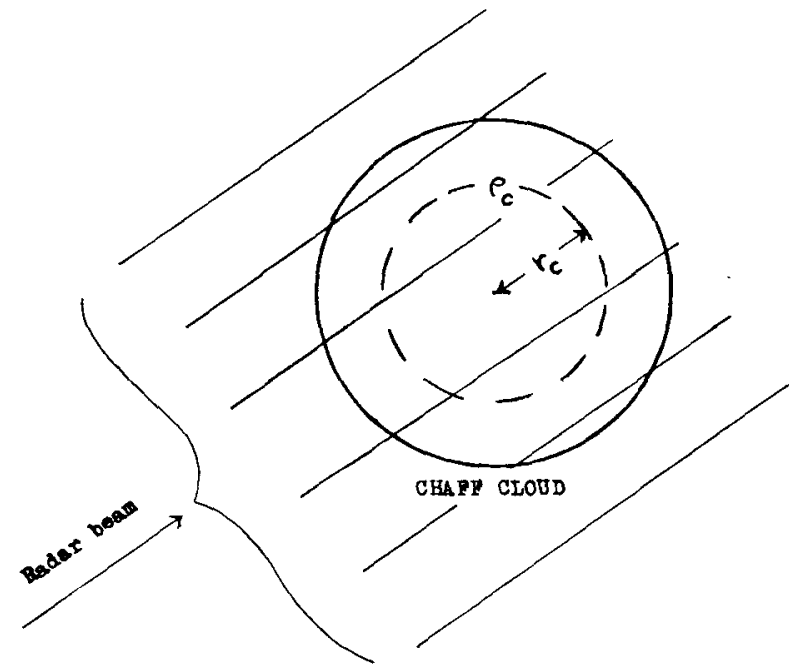

Frg. 10. Schematic diagram of chaff cloud and radar beam.

the A-scope is $W=2 r_{c}$. Therefore,

$$
\begin{aligned}
\rho_{c} & =A t^{-3 / 2} \exp \left\{-r_{o}^{2} / B t\right\}, \\
& =A t^{-3 / 2} \exp \left\{-W^{2} / 16 K t\right\},
\end{aligned}
$$

and

$$
\ln \rho_{c}=\ln A-\frac{3}{2} \ln t-W^{2} / 16 K t \text {. }
$$

Therefore,

or

$$
W^{2} / t+24 K \ln t+C=0,(C=\text { constant })
$$

$$
W^{2} / t+55.26 K \log _{10} t+C=0 .
$$

Thus, by plotting $W^{2} / t$ against $\log _{10} t$, it should be possible to estimate $K$.

The assumptions and approximations involved in the above argument are discussed in detail in an earlier paper (Rao, 1965).

\section{REFERENCES}

Batten, E. S., 1961: Wind systems in the mesosphere and lower ionosphere. J. Meteor., 18, 283-291.

Faust, H., and E. Soos, 1965: Project Cell Structure of the Atmosphere. Final Report, European Research Office, U.S. Army, 183 pp.

Groves, G. V., 1965 : COSPA R International Reference Atmosphere 1965. Amsterdam, North Holland Publishing Co., 29-88.

Kellogg, W. W., 1964: Meteorological soundings in the upper atmosphere. W. M. O. Technical Note No. 60, 46 pp.

Rahmatullah, M., and S. A. Jafri, 1965: Stratospheric wind pattern in sub-tropics based on data from meteorological sounding rocket firings during 1964-65. Space Research, VI, New York, Spartan Books (in press).

Rao, M. S. V., 1965: Results of meteorological rocket soundings at an equatorial station. Space Research, VI, New York, Spartan Books (in press).

-_ , and D. N. Sikdar, 1965: Methods of measuring winds and temperatures in the upper atmosphere with small rockets. Indian J. Meteor. Geophys., 16, 661-670. 